\title{
Coronavirus Disease - 2019 (Covid-19) Pandemic and Cancer - A Cochrane Review
}

\author{
Dr P K Prem Ravi Varma* \\ Department of Medical Oncology, Ernakulam Government Medical College Compound, Cochin Cancer Research Centre, India
}

Submission: September 28, 2020; Published: October 08, 2020

*Corresponding author: Dr P K Prem Ravi Varma, Head of Department, Department of Medical Oncology, Cochin Cancer Research Centre, ER.515/06, Ernakulam Government Medical College Compound, HMT Colony, North Kalamassery, Kochi, Kerala 683503, India

Abstract

Purpose: Whether cancer is associated with worse prognosis among patients with COVID-19 is unknown. I aimed to quantify the effect (if any) of the presence as opposed to absence of cancer on important clinical outcomes of patients with COVID-19 by carrying out a literature review in Cochrane Library.

Methods: I systematically searched Cochrane Library database, medRxiv, COVID-19 Open Research Dataset (CORD-19), and references of relevant articles up to April 27, 2020, to identify observational studies comparing patients with versus without cancer infected with COVID-19 and to report on mortality and/or need for admission to the intensive care unit (ICU).

Results: A total of 32 studies involving 46,499 patients (1,776 patients with cancer) with COVID-19 from Asia, Europe, and the United States were included. All-cause mortality was higher in patients with versus those without cancer (2,034 deaths; 8 studies with 37,807 patients). The need for ICU admission was also more likely in patients with versus without cancer (3,220 events; 26 studies with 15,375 patients). However, in a prespecified subgroup analysis of patients $>65$ years of age, all-cause mortality was comparable between those with versus without cancer (915 deaths; RR, 1.06; 95\% CI, 0.79 to $1.41 ; \mathrm{P}=.71 ; 8$ studies with 5,438 patients).

Conclusion: The synthesized evidence suggests that cancer is associated with worse clinical outcomes among patients with COVID-19. However, elderly patients with cancer may not be at increased risk of death when infected with COVID-19. These findings may inform discussions of clinicians with patients about prognosis and may guide health policies.

\section{Introduction}

\section{A photographic time capsule of COVID-19}

For most physicians, as 2020 dawned there was no indication that a pandemic illness would transform the face of healthcare within a dramatically short timeframe: today there is no indication of when we will "return to normal". Most wisdom leans towards the notion that the old normal is over. Dealing with tumultuous change is famously stressful; dealing with it while uncertain of the safety of one's loved ones, while acting out of one's main area of expertise and while feeling somewhat helpless is especially arduous. The medical community all over the world has responded in a spectacular and unambiguous way, and for all their exhaustion and dedication has been matched by the humbling sense of being part of an extraordinary local and global response. Marrying up the repercussions on the healthcare needs of the population, and hence the way services are provided with the pre-pandemic challenge to deliver personalized healthcare is the call of the present.

\section{Actions must speak louder than words}

It is important to quantify the effect of cancer on outcomes of patients with COVID-19, as there are conflicting reports in the literature. Several studies indicated that patients with cancer are more likely to develop severe disease and are at increased risk for poor prognosis [1-3]. They therefore encouraged clinicians to treat patients with cancer as an extremely vulnerable population. Those studies might also raise issues as to whether it is futile to admit patients with cancer and COVID-19 to the ICU [4]. On the other hand, other studies suggested that there was no evidence of elevated mortality rates among infected patients with cancer $[5,6]$. An interesting theory even suggested that immunocompromised patients, such as patients with cancer, may dampen the so-called "cytokine storm" because of downregulated immune response and thus have comparable or even better clinical outcomes $[7,8]$. The results of this literature review might help to reveal the true effect of cancer on mortality and need for ICU admission. 


\section{Context}

\section{Key Objective}

To quantify the effect (if any) of the presence as opposed to absence of cancer on important clinical outcomes of patients with COVID-19.

\section{Knowledge Generated}

Cancer is associated with worse clinical outcomes among patients with COVID-19. However, elderly patients with cancer may not be at increased risk of death when infected with COVID-19.

\section{Relevance}

The findings of the review may inform discussions of clinicians with patients about prognosis and may guide health policies. I therefore aimed to quantify the effect (if any) of the presence as opposed to absence of cancer on important clinical outcomes, such as mortality and need for admission in the intensive care unit (ICU), of patients with COVID-19 by carrying out a literature review.

\section{Methods}

\section{Eligibility Criteria}

I considered observational cohort studies of COVID-19, which reported on all-cause mortality and/or need for ICU admission of patients with cancer versus patients without cancer. Both peerreviewed papers and preprints were considered, because of the need for use of rapidly accumulated information during the current situation. Reports on coronavirus-caused diseases other than COVID-19 were excluded.

\section{Search Strategy}

I systematically searched Cochrane database, medRxiv, and CORD-19 (COVID-19 Open Research Dataset). The latter is probably the most extensive machine-readable literature collection specially created for the COVID-19 global crisis. I retrieved all relevant English literature from January 1, 2020, up to April 27, 2020. I also searched references of initially retrieved articles. I used Boolean logic to create the search key phrase ("clinical characteristics" OR comorbidities OR cancer OR malignancy) AND (COVID-19 OR 2019-nCoV OR SARS-CoV-2) AND (mortality OR morbidity OR severity OR ICU OR outcomes). When searching CORD-19, I replaced Boolean operators "AND" and "OR" with the symbols "+" and "l", respectively. When searching medRxiv, I used "COVID-19 cancer" as the main key phrase. I assessed the methodological quality of the retrieved observational cohort studies with the Tool to Assess Risk of Bias in Cohort Studies, developed by the CLARITY Group at McMaster University [9]. The tool uses 8 questions, with 4 possible answers in each.

\section{Outcomes of the literature review}

The primary outcomes of the literature review were allcause mortality and need for ICU admission. The latter outcome included either actual admission to the ICU or severe disease (such as application of invasive mechanical ventilation) that required admission to the ICU, even if the original study did not specify whether such patients were indeed admitted in the ICU. I did so because patients with severe disease might occasionally be unable to be admitted to the ICU because of unavailability of enough beds. Twenty-six studies (15,375 total patients, 801 with cancer) provided data for need for ICU admission. Patients with cancer were more likely to need ICU admission than patients without cancer $(3,220$ events) [10,11-18]. Eight studies $(37,807$ total patients, 1,428 with cancer) provided data for all-cause mortality [19-23]. All-cause mortality was higher in patients with versus without cancer (2,034 deaths).

My literature review has limitations. First, there are concerns for duplicate publications. In an attempt to minimize this risk, I excluded studies on mortality conducted in the same region with overlapping enrollment dates and I included only the results of the largest cohort. Second, data were not available to perform meaningful subgroup analyses by type of cancer (including treatment and immunosuppressive status). I also found that elderly patients with cancer may not be at increased risk of death when infected with COVID-19. The findings of the literature review are important to clinicians because they can inform discussions with patients about prognosis. They may also guide health policies regarding protection of this vulnerable population.

\section{Discussion - Impediments in the management of} Cancer patients with COVID-19 infection

While some risk factors have been identified, the reasons for the disparities in disease progression in cancer patients with Covid-19 are unclear, with some patients developing progressive and severe disease while in others the course is benign. Given this sense of randomness, and in the absence of a definitive treatment, medical professionals can feel helpless. It is useful to remember how much can be done to affect the trajectory of illness, even without a 'magic bullet'. With evidence emerging that late presentation is directly associated with increased mortality, we must make a case for increased vigilance in the community and earlier intervention.

An overwhelmed healthcare system does poorly, mainly due to the loss of the usual checks and balances that prevent people deteriorating in the community, presenting late and then requiring heroic measures to give them a fighting chance. If the curve has been flattened - if we have dampened the surge - and the contingencies have freed up some space, then it would be wise to use such resource to proactively identify patients at risk and 


\section{Cancer Therapy \& Oncology International Journal}

assess them regularly, while maintaining a lower threshold for admission than perhaps we are used to. Intervening early is likely to use less resources and save more lives.

The alternative is to allow patients to regulate themselves. Unless the patient has a medical degree and an oxygen saturation monitor at home, they are not in a position to determine whether they should break the 'stay at home' mantra that has gripped much of the world. Perhaps without such pressure to stay at home, people could use their normal (non-pandemic) judgment to determine when to seek medical help. They are disadvantaged further by the lack of physical contact with their community doctor. Again, assessing a patient's clinical status over the phone, with an infection we have never seen before, is asking a lot of both clinician and patient.

The battle for lives will likely be won in the community. It is the community doctors, the paramedical staff and the Emergency department staff who will shift the balance and save most lives. For most it will be, clear, sound triage systems and clear clinical guidelines that will determine the mortality rate probably much more than the total number of ventilators available. As cancer patients contend with COVID-19 it is critical to ensure that the nutritional needs of the population are met and sustained, including those who are most vulnerable. Prevention, diagnosis and treatment of malnutrition must also be included in the routine management of COVID-19 inpatients. We as clinicians should adapt traditional nutritional care pathways to allow temporary mechanisms for pragmatic and safe decision-making.

This period could be looked upon as an opportunity. The onus is on those in authority to promote and facilitate a nutritional culture, on the population to achieve behavior change and on healthcare professionals to embed nutritional care into routine practice. None of these measures are new or groundbreaking, but perhaps have not been at the forefront in recent years. If we are collectively able to implement and sustain these strategies during and after this pandemic, there may be at least one positive legacy of COVID-19. Necessity is, after all, the mother of (re)invention.

Early data from the outbreak suggest that $80 \%$ of patients develop mild symptoms, $15 \%$ severe symptoms and $5 \%$ become critically ill [24]. A case series of 138 hospitalised patients from Wuhan (China) has identified hypertension, diabetes and previous cardiovascular disease as risk factors for intensive care admission [25]. The median age of hospitalized patients was 51, compared to 66 for those admitted to intensive care [25]. The Centre of Perioperative Care in the United Kingdom has already issued expert guidance advocating for 'brisk exercise', smoking cessation, alcohol-free days and good nutrition as preventative measures in this outbreak $[26,27]$.

Social prescribing is the idea that people's health is determined by a range of social, economic and environmental factors, and seeks to treat patients in a holistic way. It also aims to support individuals to take greater control of their own health..

\section{References}

1. Zhang HY, Wang LW, Chen YY, Xiao-Kun Shen, Qun Wang, et al. (2020) A multicentre study of 2019 novel coronavirus disease outcomes of cancer patients in Wuhan, China. medRxiv.

2. Zhang L, Zhu F, Xie L, C Wang, J Wang, et al. (2020) Clinical characteristics of COVID-19-infected cancer patients: A retrospective case study in three hospitals within Wuhan, China. Ann Oncol 31(7): 894-901.

3. Ma J, Yin J, Qian Y, (2020) Clinical characteristics and prognosis in cancer patients with COVID-19: A single center's retrospective study. J Infect 81(2): 318-356.

4. Koutsoukou A (2017) Admission of critically ill patients with cancer to the ICU: Many uncertainties remain. ESMO Open 2: e000105.

5. Miyashita H, Mikami T, Chopra N, T Yamada, S Chernyavsky et al. (2020) Do patients with cancer have a poorer prognosis of COVID-19? An experience in New York City. Ann Oncol 31(8): 1088-1089.

6. Narozniak R (2020) Clinical factors predict deterioration among patients with cancer, COVID-19?

7. Joharatnam-Hogan N, Hochhauser D, Shiu K-K, Hannah Rush, Valerie Crolley, et al. (2020) Outcomes of the 2019 novel coronavirus in patients with or without a history of cancer - a multi-centre North London experience. medRxiv.

8. Spezzani V, Piunno A, Iselin HU (2020) Benign COVID-19 in an immunocompromised cancer patient - the case of a married couple. Swiss Med Wkly 150: w20246.

9. Cai Q Huang D, Ou P, Hong Yu, Zhibin Zhu, et al. (2020) COVID-19 in a designated infectious diseases hospital outside Hubei Province, China. Allergy 75(7): 1742-1752.

10. Benelli G, Buscarini E, Canetta C, Giuseppe La Piana, Guido Merli, et al (2020) SARS-COV-2 comorbidity network and outcome in hospitalized patients in Crema, Italy. medRxiv.

11. Argenziano MG, Bruce SL, Slater CL, Jonathan RT, Matthew R Baldwin, et al. (2020) Characterization and clinical course of 1000 patients with COVID-19 in New York: Retrospective case series. medRxiv.

12. Cao M, Zhang D, Wang Y, Yunfei Lu, Xiangdong Zhu, et al. (2020) Clinical features of patients infected with the 2019 novel coronavirus (COVID-19) in Shanghai, China. medRxiv.

13. Chen X, Zheng F, Qing Y, Shuizi Ding, Danhui Yang, et al. (2020) Epidemiological and clinical features of 291 cases with coronavirus disease 2019 in areas adjacent to Hubei, China: A double-center observational study. medRxiv.

14. Colaneri M, Sacchi P, Zuccaro V, Simona Biscarini, Michele Sachs, et al. (2020) Clinical characteristics of coronavirus disease (COVID-19) early findings from a teaching hospital in Pavia, North Italy, 21 to 28 February 2020. Euro Surveill 25: 2000460.

15. Feng Y, Ling Y, Bai T, Yusang Xie, Jie Huang, et al. (2020) COVID-19 with different severity: A multi-center study of clinical features. Am J Respir Crit Care Med 201(11): 1380-1388.

16. Guan WJ, Liang WH, Zhao Y, Heng-Rui Liang, Zi-Sheng Chen, et al (2020) Comorbidity and its impact on 1590 patients with COVID-19 in China: A nationwide analysis. Eur Respir J 55:2000547.

17. Huang C, Wang Y, Li X, Lili Ren, Jianping Zhao, et al. (2020) Clinical features of patients infected with 2019 novel coronavirus in Wuhan, China. Lancet 395( 10223): 497-506. 


\section{Cancer Therapy \& Oncology International Journal}

18. Jiang $X$, Tao J, Wu H, Yixin Wang, Wei Zhao, et al. (2020) Clinical features and management of severe COVID-19: A retrospective study in Wuxi, Jiangsu Province, China. medRxiv.

19. The Novel Coronavirus Pneumonia Emergency Response Epidemiology Team: The epidemiological characteristics of an outbreak of 2019 novel coronavirus diseases (COVID-19) — China, 2020.

20. Goyal P, Choi JJ, Pinheiro LC (2020) Clinical characteristics of Covid-19 in New York City. N Engl J Med.

21. Nikpouraghdam M, Jalali Farahani A, Alishiri G, Soleyman Heydari, Mehdi Ebrahimnia, et al. (2020) Epidemiological characteristics of coronavirus disease 2019 (COVID-19) patients in Iran: A single center study. J Clin Virol 127: 104378.

22. Rentsch CT, Kidwai-Khan F, Tate JP, Lesley S Park, Joseph T King, et al. (2020) Covid-19 testing, hospital admission, and intensive care among 2,026,227 United States Veterans aged 54-75 years. medRxiv.
23. Rossi PG, Marino M, Formisano D, Francesco Venturelli, Massimo Vicentini, et al. (2020) Characteristics and outcomes of a cohort of SARS-CoV-2 patients in the Province of Reggio Emilia, Italy. medRxiv.

24. Razai M, Doerholt K, Ladhani S, Oakeshott P (2020) Coronavirus disease 2019 (COVID-19): a guide for UK GPs. BMJ 368: m800.

25. Wang D, Hu B, Hu C, Fangfang Zhu, Xing Liu, et al. (2020) Clinical characteristics of 138 hospitalized patients with 2019 novel coronavirus-infected pneumonia in Wuhan, China. JAMA 2020 323(11): 1061-1069.

26. O'Connor M (2020) Stay fit to fight coronavirus, say medics. BBC News, 28 March 2020.

27. Tool to Assess Risk of Bias in Cohort Studies. Contributed by the CLARITY Group at McMaster University (2017).

\section{Your next submission with Juniper Publishers} will reach you the below assets

- Quality Editorial service

- Swift Peer Review

- Reprints availability

- E-prints Service

- Manuscript Podcast for convenient understanding

- Global attainment for your research

- Manuscript accessibility in different formats ( Pdf, E-pub, Full Text, Audio)

- Unceasing customer service

Track the below URL for one-step submission https://juniperpublishers.com/online-submission.php 